\title{
On the opportunity cost of crop diversification
}

Article

Accepted Version

Ang, F., Mortimer, S., Areal, F. and Tiffin, R. (2018) On the opportunity cost of crop diversification. Journal of Agricultural Economics, 69 (3). pp. 794-814. ISSN 1477-9552 doi: https://doi.org/10.1111/1477-9552.12272 Available at https://centaur.reading.ac.uk/75139/

It is advisable to refer to the publisher's version if you intend to cite from the work. See Guidance on citing.

To link to this article DOI: http://dx.doi.org/10.1111/1477-9552.12272

Publisher: Wiley

All outputs in CentAUR are protected by Intellectual Property Rights law, including copyright law. Copyright and IPR is retained by the creators or other copyright holders. Terms and conditions for use of this material are defined in the End User Agreement.

\section{www.reading.ac.uk/centaur}

\section{CentAUR}

Central Archive at the University of Reading

Reading's research outputs online 
4 [Original submitted April 2017, Revision received October 2017, Accepted January 2018]

5 Abstract

6 Distance functions are increasingly being augmented, with environmental goods treated as conventional outputs. A common approach to evaluate the opportunity cost of providing an environmental good is the exploitation of the distance function's dual relationship to the value function. This implies that the opportunity cost is assumed to be non-negative. This approach also requires a convex technology set. Focusing on crop diversification for a balanced sample of 44 cereal farms in the East of England for the years 2007-2013, this paper develops a novel opportunity cost measure that does not depend on these strong assumptions. We find that the opportunity cost of crop diversification is negative for most farms.

Keywords biodiversity, CAP greening measures, Shannon index, non-convexity, shadow price, duality, crop diversification

1 Frederic Ang is the contact author, frederic.ang@wur.nl, and is in the Business Economics Group, Wageningen University, Wageningen, Netherlands. Simon Mortimer is in the Centre for AgriEnvironmental Research, University of Reading, UK. Francisco Areal and Richard Tiffin are both with the Agri-Food Economics and Social Sciences Research Group, School of Agriculture, Policy and Development, University of Reading, UK. We thank the editor and three anonymous reviewers for their valuable comments and suggestions. This paper has benefitted substantially from inspiring discussions with Liza Archanskaia, Laurens Cherchye, Veerle Hennebel, Pieter Jan Kerstens, Alfons Oude Lansink and Lotte Ovaere. We acknowledge the financial support from the UK Department for the Environment, Food and Rural Affairs (Sustainable Intensification Platform Project 1). Any remaining errors are the responsibility of the authors. 


\section{Introduction}

Agriculture not only provides economic outputs, but also generates externalities including environmental goods (e.g., landscape conservation and habitat for birds) and 'bads' (e.g., nitrogen and phosphorus surplus due to fertiliser use). Environmental goods and bads are nonmarketed, and may call for government intervention to deal with or internalise these external benefits and costs to align consumers' and producers' interests (Areal, Tiffin et al., 2012). A large body of economic literature assesses the trade-off between production and externalities. Externalities have commonly been implemented in a distance function framework, to estimate environmental efficiency and productivity measures. The shadow price of an externality can be computed by exploiting the distance function's dual relationship to the value function. Knowing the shadow price of an externality is useful for policy makers, who may set up schemes to compensate for the potential financial losses incurred by the farmers.

Studies originally focused on environmental bads. Examples in the agricultural sector include nitrogen surplus (Piot-Lepetit and Vermersch, 1998; Reinhard, Lovell et al., 1999; Piot-Lepetit and Le Moing, 2007), phosphorus surplus (Reinhard, Lovell et al., 2000; Coelli, Lauwers et al., 2007), pesticide pollution (Oude Lansink and Silva, 2004; Chambers, Serra et al., 2014; Serra, Chambers et al., 2014) and greenhouse gas emission (Oude Lansink and Silva, 2003; Dakpo, Jeanneaux et al., 2017).

The literature has increasingly identified an interest in augmenting distance functions with environmental goods. To the best of our knowledge, Färe, Grosskopf et al. (2001) are the first to adopt this approach, focussing on non-marketed characteristics of conservation land in the United States. Other studies extend the distance function with the extent of wetland and interior forest (Macpherson, Principe et al., 2010), six key indicators of biotic integrity of watershed data (Bellenger and Herlihy, 2009; Bellenger and Herlihy, 2010), the extent of permanent grassland (Areal, Tiffin et al., 2012), cultural services, biodiversity, carbon sequestration and the extent of arable and grassland (Ruijs, Wossink et al., 2013; Ruijs, Kortelainen et al., 2017), the Shannon index for crop diversity (Sipiläinen and Huhtala, 2013), and wetland quality (Bostian and Herlihy, 2014). Färe, Grosskopf et al. (2001), Bellenger and Herlihy (2010), Ruijs, Wossink et al. (2013), Sipiläinen and Huhtala (2013), Bostian and Herlihy (2014) and Ruijs, Kortelainen et al. (2017) compute the shadow price of their environmental goods by exploiting the output distance function's dual relationship to the revenue function.

These studies' distance function approach has two important limitations, which can lead to an incorrect assessment of the opportunity cost of the considered environmental good. First, it is 
assumed that an environmental good can be treated as a conventional, strongly disposable output and that its shadow price is consequently always non-negative. Second, it is necessary to assume that the augmented environmental technology set is convex, to ensure that the distance function's dual relationship to the value function holds.

Both assumptions are very strong. The strong disposability assumption implies that the provision of an environmental good is assumed to be non-increasing for increases in the output level. However, several contributions argue that some environmental goods are complementary to conventional production for lower levels of the environmental good, and competitive for higher levels (Harvey, 2003; Hodge, 2008). This means that the shadow price of an environmental good could also be negative. Such a complementary-competitive relationship is hypothesized for inter alia the environmental quality of grassland and livestock production (Vatn, 2002), pollinator habitat and crop production (Wossink and Swinton, 2007), and the entire ecosystem on the farm and total agricultural production (Hodge, 2000). The strong disposability assumption also implies that the provision of an environmental good is assumed to be non-decreasing for increases in the input level. As shadow-pricing of environmental goods inherently focuses on the trade-off between the environmental good and the conventional output, this has generally been left undiscussed by the literature. However, there is no theoretical reason to assume this a priori. Ruijs, Wossink et al. (2013) and Ruijs, Kortelainen et al. (2017) seem to be the only authors that check the transformation function empirically and confirm the theorised relationships. Nonetheless, this remains a contested assumption for which the theoretical basis is lacking and the evidence is scarce. We believe that this assumption is especially problematic for inputs that increase the provision of environmental bads such as pesticides and fertilisers.

More and more studies argue that the environmental technology set is non-convex (Di Falco and Chavas, 2009; Chavas and Di Falco, 2012). The convexity assumption is invoked for analytical rather than theoretical reasons (Pope and Johnson, 2013). Again, Ruijs, Wossink et al. (2013) and Ruijs, Kortelainen et al. (2017) seem to be the only authors that empirically test the convexity assumption. They do not find evidence of convexity. This implies that their resulting opportunity costs do not maximise benefits and should not be used to design a pricing mechanism.

We focus on the Shannon index for crop diversity. This index was also the focus for Sipiläinen and Huhtala (2013), who computed its shadow price using the dual relationship of the distance function to the revenue function. Crop diversity has been shown to be linked with inter alia long-term stability of the carbon stock in the soil (Henry, Tittonell et al., 2009), improved 
nutrient balance (Pimentel, Hepperly et al., 2005) and landscape diversity (Westbury, Park et al., 2011). In the context of crop production, it measures the crop diversity by representing the number of crop types and evenness of the area covered by the crops. Considering the number of crop types as well as evenness, the Shannon index for crop diversity is an essential determinant of sustainable food supply (Aguilar, Gramig et al., 2015). From an ecological perspective, it is thus important to increase the Shannon index for crop diversity. Various studies in the economics literature use the Shannon index for crop diversity as an environmental good (e.g., Weitzman, 2000; Di Falco and Chavas, 2008; Sipiläinen and Huhtala, 2013).

Correct assessment of the opportunity cost of crop diversification is also relevant given the 'Green Direct Payment' measure introduced recently in 2015 by the European Common Agricultural Policy (CAP), which holds for all member states of the European Union. This measure links thirty percent of the direct payments to the provision of environmental goods. One condition for receipt of these payments is the ' 2 or 3 crop rule' (European Parliament, 2013). This regulation imposes minimum requirements on the number of crops and their proportional cover, which is conceptually in line with the Shannon index for crop diversity. Farms of 10-30 ha should grow at least two crops, with the main crop covering at most $75 \%$ of the arable land. Farms larger than 30 ha should grow at least three crops, with the main crop covering at most $75 \%$ of the arable land, and two crops covering a maximum of $95 \%$ of the arable land. In summary, the Shannon index for crop diversity is relevant in terms of both ecological benefits and policy.

Given the theoretical concerns of shadow-pricing environmental goods using the distance function approach, we compute the opportunity cost of crop diversification in a novel way. Our proposed method is conceptually straightforward. If we use a credible assumption of economic behaviour and its corresponding Shannon index for crop diversity, we can accurately compute the opportunity cost of crop diversification. Such an approach separates the environmental good from the production technology and does not necessarily require a convex technology set, thus overcoming the axiomatic problems associated with shadow-pricing using the distance function approach.

We operationalise our proposal using recent methodological developments in the literature. Cherchye, De Rock et al. (2017) show how one can take into account the output-specific character of inputs and the extent to which reallocation of these inputs over outputs can increase efficiency. We adapt their input distance function framework to Ang and Oude Lansink (2017)'s dynamic profit-maximisation framework and focus on the optimal reallocation of output-specific land use. Using a nonparametric model, we assess the extent to which 
reallocation of land use can increase current-value profit. We express the opportunity cost of increasing the Shannon index for crop diversity in terms of foregone current-value profit. Doing so allows us to calculate the opportunity cost of crop diversification in a way that avoids implementing the environmental good in the technology set and thus imposes less stringent assumptions on the axiomatic properties of the technology set. Our proposed approach is consistent with the behavioural assumption of dynamic profit-maximisation. Finally, we are able to assess the extent to which farmers would have complied with the CAP's novel ' 2 or 3 crop rule' should they have optimally reallocated their land use. The application focuses on a balanced sample of 44 cereal farms in the East of England for the years 2007-2013.

The remainder of this paper is structured as follows. The next section explains our method. This is followed by a description of the data. The results are presented and discussed in the subsequent sections. The final section concludes.

\section{Method}

Following Ang and Oude Lansink (2017), farms are faced with a dynamic, intertemporal profitmaximisation problem where they are price takers in competitive input, output and capital markets, and have identical, static expectations on the discount and depreciation rates. It is assumed that the farms maximise the discounted flow of profits over time at any base time period, while being restricted by the adjustment-cost technology. The latter assumption coincides with the perspective that farms cannot instantaneously adjust quasi-fixed inputs to their long-term optimal levels and investments are coupled with adjustment costs (Silva and Stefanou, 2003; Silva, Oude Lansink et al., 2015). The (variable) intertemporal profitmaximisation problem is (Ang and Oude Lansink, 2017):

(1) $W\left(p, K_{t}, w, c\right)=\max _{\{y(.), x(.), I(.)\}} e^{-r(s-t)} \int_{t}^{+\infty}\left[p^{\prime} y(s)-w^{\prime} x(s)\right] d s$

s.t.

(2) $\frac{d K(s)}{d t}=I(s)-\delta K(s)$ with $K(t)=K_{t}$

(3) $\vec{D}_{T}\left(y(s), x(s), I(s), K(s), G(s), L(s) ; g_{y}, g_{x}, g_{I}\right) \geq 0$ with $s \in[0,+\infty[$

where $W($.$) is the current value form of dynamic profit-maximisation, y \in \mathbb{R}_{+}^{M}$ is the crop output vector, $x \in \mathbb{R}_{+}^{N}$ is the variable input vector, $K_{t} \in \mathbb{R}_{+}^{F}$ is the initial capital stock vector, $I \in \mathbb{R}_{+}^{F}$ is the investment vector, $L \in \mathbb{R}_{+}^{M}$ is the crop-specific land vector, $G \in \mathbb{R}_{+}^{Z}$ is the vector of non-reallocatable fixed factors, $p \in \mathbb{R}_{++}^{M}$ is the vector of output prices, $w \in \mathbb{R}_{++}^{N}$ is the vector of input prices, $r>0$ is the rental rate, $\delta$ is a diagonal $F \times F$ matrix of depreciation rates $\delta_{f}>$ 
$1530, f, \ldots, F$ and $\vec{D}_{T}($.$) is the dynamic directional distance function with the corresponding$ 154 directional vector in terms of outputs, inputs and investments $\left(g_{y}, g_{x}, g_{I}\right)$. Eqs. (2) and (3) 155 denote the equation of motion and the dynamic technology, respectively. For a full 156 characterization of the dynamic directional distance function (extended with the net investment 157 vector), we refer to the appendix of Ang and Oude Lansink (2017).

158 In line with Cherchye, De Rock et al. (2013) and Cherchye, De Rock et al. (2017), we make a 159 distinction between joint and output-specific inputs. A joint input cannot be allocated to one 160 specific output and is thus needed for the production of multiple outputs. An output-specific 161 input is allocated to one particular output. Variable and fixed non-reallocatable inputs are joint 162 inputs. Land is our considered output-specific input. This approach is a more realistic 163 representation of the production technology and allows for increased detection of nonmaximising farms.

165 Omitting the time indicators for simplicity, the current-value formulation of Eqs. (1) - (3) is 166 (Ang and Oude Lansink, 2017):

$$
\text { (4) } r W(p, K, w, c)=\max _{\{y, x, I\}}\left\{p^{\prime} y-w^{\prime} x+W_{K}(p, K, w, c)^{\prime}\left(I-\delta^{\prime} K\right)\right\}
$$

s.t.

(5) $\vec{D}_{T}\left(y, x, I, K, G, L ; g_{y}, g_{x}, g_{I}\right) \geq 0$ where $W_{K}($.$) is the shadow value of capital. W_{K}($.$) indicates the increase in current-value profit$ for a one-unit increase in net investment. It is an implicit, endogenous variable. Nonetheless, as all input prices and output prices are known, we can obtain farm-specific values for $W_{K}($.$) by$ 173 solving a minimax problem following Kuosmanen, Kortelainen et al. (2010) (see Appendix A). 174 In what follows, we operationalise Eqs. (4) - (5) using a nonparametric approach. We note that 175 the empirical analyst may also opt for a parametric approach, which can be more convenient for statistical comparisons. However, this requires a specification of the functional form, which

177 is prone to violations of regularity conditions. The nonparametric approach does not violate any 178 regularity conditions by construction, not requiring any specification of a functional form. In 179 addition to these general remarks, a nonparametric approach is very suitable for this application 180 in particular. First, our paper focuses on computing farm-specific opportunity costs of crop 181 diversification rather than coefficients or elasticities. Second, there are several recent 182 methodological advances in the nonparametric literature, apt for this application. By 183 specifically characterising the inputs as output-specific or joint, and allowing for reallocation 
184 possibilities of output-specific inputs (in our case land use), one can model the production 185 process on the farm in a detailed way.

186 We assume that the production technology satisfies the standard properties of closedness, 187 boundedness, strong disposability of inputs, outputs and investments, and variable returns to 188 scale (see e.g. Färe and Grosskopf, 2005). The benchmark scenario (A) is solved for each farm $189 j \in \mathbb{R}_{+}^{J}$ :

190

$$
\text { (A) } \quad r W(p, w, K, c)^{(1)}=\max _{\{y, x, I, \gamma\}}\left\{p^{\prime} y-w^{\prime} x+W_{K}(.)^{\prime}(I-\delta K)\right\}
$$
s.t.

(A.1) $\quad y_{m} \leq \sum_{j=1}^{J} \gamma_{m}^{j} y_{m}^{j}, m=1, \ldots, M$

(A.2) $\quad \sum_{j=1}^{J} \gamma_{m}^{j} x^{j} \leq x_{n}, m=1, \ldots, M, n=1, \ldots, N$

$$
\gamma_{m}^{j} \geq 0, m=1, \ldots, M, j=1, \ldots, J
$$

where $\gamma_{m}^{j} \in \mathbb{R}_{+}^{M}$ are output-specific intensity weights. (A.1), (A.2), (A.3), (A.4) and (A.5) impose strong disposability on the inputs, outputs, net investments, non-reallocatable fixed inputs and reallocatable fixed inputs. (A.6) imposes variable-returns-to-scale. (A.7) ensures non-negativity of the intensity weights. The fixed factors are not included in the objective function, but affect current-value profit through the intensity weights $\gamma_{m}^{j}$ in the constraints. Following Färe, Grabowski et al. (1997), Ang and Kerstens (2016) and Cherchye, De Rock et al. (2015); Cherchye, De Rock et al. (2017), the preceding intertemporal profit-maximisation problem can also be adapted to programme (B) where land use $L_{m}$ is optimally reallocated among $M$ crops for each farm $j \in \mathbb{R}_{+}^{J}$ :

(B) $\quad r W(p, w, K, c)^{(2)}=\max _{\left\{y, x, I, L_{m}^{*}, \gamma\right\}}\left\{p^{\prime} y-w^{\prime} x+W_{K}(.)^{\prime}(I-\delta K)\right\}$ s.t.

$$
y_{m} \leq \sum_{j=1}^{J} \gamma_{m}^{j} y_{m}^{j}, m=1, \ldots, M
$$

$$
\sum_{j=1}^{J} \gamma_{m}^{j} x^{j} \leq x_{n}, m=1, \ldots, M, n=1, \ldots, N
$$

$$
\left(I_{f}-\delta_{f} K_{f}\right) \leq \sum_{j=1}^{J} \gamma_{m}^{j}\left(I_{f}^{j}-\delta_{f} K_{f}^{j}\right), m=1, \ldots, M, f=1, \ldots, F
$$


(B.4) $\quad \sum_{j=1}^{J} \gamma_{m}^{j} G^{j} \leq G_{z}, m=1, \ldots, M, z=1, \ldots, Z$

(B.5) $\quad \sum_{j=1}^{J} \gamma_{m}^{j} L_{m}^{j} \leq L_{m}^{*}, m=1, \ldots, M$

(B.6) $\bar{L}=\sum_{m=1}^{M} L_{m}^{*}, m=1, \ldots, M$

$\sum_{j=1}^{J} \gamma_{m}^{j}=1, m=1, \ldots, M$

$$
\gamma_{m}^{j} \geq 0, m=1, \ldots, M, j=1, \ldots, J
$$

(B.1), (B.2), (B.3), (B.4), (B.7) and (B.8) are equivalent to (A.1), (A.2), (A.3), (A.4), (A.6) and (A.7), respectively. Output-specific land use is endogenised and is thus an explicit choice variable $L_{m}^{*}$ in constraint (B.5). Constraint (B.6) ensures that the sum of the optimal land uses is equal to the total land area $\bar{L}$.

Programmes (A) and (B) are linear and thus follow the Data Envelopment Analysis (DEA) approach. DEA assumes convexity of the technology set, as the frontier consists of convex combinations of resource allocations of dominating peers, resulting in a piecewise linear frontier. The convexity assumption is contested less for a production technology with only conventional inputs and outputs (as in problems (A) and (B)) than for a production technology augmented with environmental goods or bads (as is commonly done in the literature to compute environmental efficiency and productivity measures and corresponding shadow prices). However, this assumption may still be strong in the agricultural context, where various types of capital equipment are non-divisible (Ang and Kerstens, 2017). Being the main approach in the economics literature, our paper chiefly focuses on the DEA models. Nonetheless, it is important to point out that convexity of the technology set is not a necessary condition for our dynamic profit-maximisation problems. Varian (1984) and Kuosmanen (2003) show that static profit maximisation does not require convexity of the technology set. The profit-maximising resource allocations subject to a non-convex technology set can be computed using the Free Disposal Hull (FDH) method (Briec, Kerstens et al., 2004). Adapting this reasoning from a static to a dynamic context, we run such FDH models as a robustness check for non-convexity of the technology set. The FDH models are similar to the DEA models, being the solutions to programmes (A) and (B), but with binary intensity variables (i.e. $\gamma_{m}^{j} \in[0,1]$ ). This adjustment results in mixed-integer programmes by which the dynamic profit-maximising resource allocation is determined by the resource allocation of only one dominating peer.

242 The gain in current-value profit from optimally reallocating land use is:

(6) $\Delta r W()=.r W(.)^{(2)}-r W(.)^{(1)}$ where $\Delta r W() \geq$. 
244 The Shannon index for crop diversity $S\left(L_{m}, G_{\text {fallow }}\right)$ is the environmental good considered in our analysis. It is a function of output-specific land use $L_{m}$ and fallow land $G_{\text {fallow }}$ :

(7) $S\left(L_{m}, G_{\text {fallow }}\right)=-\sum_{m=1}^{M}\left[\frac{L_{m}}{L+G_{\text {fallow }}} * \ln \frac{L_{m}}{L+G_{\text {fallow }}}\right]-\frac{G_{\text {fallow }}}{L+G_{\text {fallow }}} * \ln \frac{G_{\text {fallow }}}{L+G_{\text {fallow }}}$

In line with the CAP's ' 2 or 3 crop rule', an area left fallow is counted as crop land use.

248 Programme (B) seeks for the land allocation under dynamic profit maximisation. We are able

249 to compute the Shannon index for crop diversity associated with the current allocation $S(.)^{(1)}$, 250 on the one hand, and the land allocation under dynamic profit maximisation $S(.)^{(2)}$, on the other. We define the change in the Shannon index for crop diversity due to optimal reallocation of land use as:

(8) $\Delta S()=.S(.)^{(2)}-S(.)^{(1)}$ where $\Delta S(.) \lesseqgtr 0$

Finally, we assess the trade-off between current-value profit and the Shannon index by the ratio of Eq. (6) to Eq. (8). In line with Sipiläinen and Huhtala (2013), we normalise by total land area:

(9) $\alpha=\frac{-\Delta r W(.) / \Delta S(.)}{10 *\left(L+G_{\text {fallow }}\right)}$

where $\alpha$ is the opportunity cost of the Shannon index as it measures the foregone current-value profit of increasing the Shannon index by 0.1 per unit of land. A positive (negative) $\alpha$ indicates that greater crop diversity decreases (increases) current-value profit. As for shadow pricing by the distance function approach, it indicates a willingness to accept (pay) to increase the Shannon index by 0.1 per unit of land and is expressed in $£$ per hectare. A few comments are in order here. The Shannon index for crop diversity increases with the number of crops and evenness of the area covered by the crops. For a given number of crops, a farm can maximise its Shannon index by using an even distribution of crop areas. Although an increase in the Shannon index is generally beneficial in ecological terms, prudence is required in its interpretation. First, being an integrative measure, some information inevitably becomes masked. The Shannon index does not provide information about the exact crop shares. This is particularly relevant for the optimal crop shares under dynamic profit maximisation, where more profitable products (e.g. barley) can be more difficult to sell on the market or constrained by limitations on crop rotation. We therefore also discuss the change in land use corresponding to the optimal change in the Shannon index for crop diversity. Second, the Shannon index is sensitive to scale. A larger area leads in general to a higher species richness and as a result a higher Shannon index for crop diversity. Following Sipiläinen and Huhtala (2013), one may 
choose between an ecologically meaningful scale and an economically meaningful scale. In line

276 with their study, our application opts for the latter, as we are interested in computing farmspecific opportunity costs of crop diversification. The farm level is also the relevant scale in the ' 2 or 3 crop rule' recently introduced by the CAP.

279 By not implementing an environmental good in the production technology, we avoid making 280 questionable assumptions about the production technology and do not predetermine the sign of 281 the opportunity cost. Our approach does not depend on (1) a non-negative relationship between 282 input use and production of the environmental good, (2) a non-negative trade-off between conventional production and production of the environmental good and (3) convexity of the production technology.

285 The interpretation of the opportunity cost is not exactly the same as the shadow price obtained by exploiting duality. Shadow pricing in the augmented distance function framework is essentially a marginal concept which relies on convexity of the environmental technology set. Eq. (9) shows that $\alpha$ should be interpreted as the average foregone current-value profit of increasing the Shannon index by 0.1 unit. Our approach is somewhat similar to that of Coelli, Lauwers et al. (2007), who avoid implementing the environmental "bad" (pollutant) in the production technology. They construct "shadow cost estimates" (p. 11) as opportunity costs by calculating the ratio of the difference between costs under minimised pollution and minimised costs, to the difference between minimised pollution and pollution under minimised costs. Throughout this paper, we use the term "opportunity cost" rather than "shadow price" or "shadow cost", as the latter terms may have the connotation of differentiability of the technology set.

\section{Data}

We use data from the Farm Business Survey (FBS) dataset for the years 2007-2013. The FBS dataset provides farm-level information on economic and physical characteristics for a large

300 sample of English and Welsh farms. We distinguish eight marketable crop outputs (wheat, 301 barley, oats, beans, peas, potatoes and sugar beet, and 'other outputs' ${ }^{2}$ ), eight variable inputs 302 (seed and planting stock, fertilizer, crop protection, electricity, heating fuel, external labour, management and 'other variable inputs'), two quasi-fixed inputs (buildings and machinery), one fixed output-specific input that can be reallocated (output-specific land) and two fixed non-

\footnotetext{
2 The 'other outputs' category consists of outputs that cannot be counted as separate crop types following the CAP's ' 2 or 3 crop rule'. Although its corresponding land use is assumed to be reallocatable, it does not enter the calculation of the Shannon index for crop diversity.
} 
reallocatable inputs (residual land and family labour). Hired labour and management are expressed in annual working hours. Using price indexes obtained from the EUROSTAT (2015) database, we express the prices of crop outputs, the remaining variable inputs and the investments in quasi-fixed inputs in constant $2007 £$. Implicit aggregated quantities are computed for 'other outputs' by using Törnqvist price indexes. All outputs include subsidies, but exclude direct payments. The historical depreciation of quasi-fixed inputs is obtained directly from the FBS dataset and also expressed in constant $2007 £$. (Residual) land and family labour are measured respectively in hectares and annual working hours. Variable inputs and fixed non-reallocatable inputs are joint inputs. Note that some variable inputs (e.g., purchased seeds for wheat production) could in theory be output-specific, but that such a specification is not possible due to a lack of data. As residual land contains permanent grassland and other herbaceous forage and fallow land, it improves the nutrient cycling in the soil and benefits the overall production of the marketable outputs. Therefore, these land inputs are also assumed to 318 be joint.

319 We only consider specialised crop farms in the East of England that do not produce any livestock during the total time period, to obtain a homogenous sample. The FBS rotates the sample in such a way that every farm stays in the sample for five to seven years on average. We use a balanced dataset of 44 observations per year for a period of seven years to maximise the number of analysed years. Table 1 shows the summary statistics of the dataset. INSERT TABLE 1 AROUND HERE

\section{Results}

This section is structured as follows. First, we show the main results, where we show the maximum current-value profits obtained using DEA problems (A) and (B), the corresponding Shannon indices and the implied opportunity costs of crop diversification. Then, we conduct several robustness checks to examine the validity of our main results. This section ends with a comparison to the opportunity costs obtained employing Sipiläinen and Huhtala (2013)'s approach, which per usual exploits the distance function's dual relationship to the value function.

\subsection{Main Results}

334 DEA problems (A) and (B) are run for each farm in the sample in each year. This procedure controls for shifts of the frontier in time due to technical progress and fluctuating weather conditions. We report the main results in Tables 2-4 and Figure 1. The monetary values are expressed in constant $2007 £$ in what follows. 
338 Table 2 shows the actual and maximum current-value profit and corresponding Shannon indices

339 for crop diversity for DEA problems (A) and (B). The actual current-value profit is on average $340 £ 123,900$ for all years considered. There is substantial heterogeneity per year, indicating that 341 fluctuating weather conditions play an essential role: while the actual current-value profit 342 reaches on average $£ 210,096$ in 2012 , it is on average only $-£ 38,429$ in 2009 . Assuming that 343 the actual land allocation is fixed, the maximum current-value profit is on average $£ 157,407$ 344 for DEA problem (A) for all years considered. Allowing for optimal reallocation of land use, 345 the maximum current-value profit is on average $£ 195,488$ for DEA problem (B). The increase 346 in maximum current-value profit is associated with an increase in the Shannon index for crop 347 diversity from on average 0.85 to 1.13 for all years considered. This pattern is consistent for the 348 whole period.

\section{INSERT TABLE 2 AROUND HERE}

350 Figure 1 illustrates the change in land use in percentage units that corresponds to the optimal 351 change in the Shannon index for crop diversity. It suggests that some land use allocated to 352 wheat, beans and potatoes should shift towards barley, peas, oats and sugar beet. This pattern 353 generally holds, although there are annual fluctuations possibly due to changing market and 354 weather conditions. Note that market conditions and restrictions on crop rotation may prevent 355 farmers from optimally allocating land use. For instance, since wheat is highly marketable, 356 farmers may choose to continue producing at a higher level than the level suggested by our 357 dynamic profit-maximisation model.

\section{INSERT FIGURE 1 AROUND HERE}

359 Table 3 shows the computed opportunity costs of crop diversification obtained by Eq. (9). In 360 what follows, we express the opportunity cost as the average cost (in constant $2007 £$ ) of increasing the Shannon index by 0.1 unit per hectare. The average opportunity cost is - $£ 101$ for the period, ranging from - $£ 244$ (in 2009) to $£ 34$ (in 2007), where only one year shows an average positive opportunity cost. This means that farms are on average willing to pay for crop 364 diversification.

$36567 \%$ of the full sample have a negative opportunity cost for crop diversification. The majority 366 of the farms are thus willing to pay for an increase in the Shannon index for crop diversity. 19\% 367 of the calculated opportunity costs are zero, and only $15 \%$ are positive. This proportion is consistent for the whole time period.

\section{INSERT TABLE 3 AROUND HERE}

370 Table 4 presents the actual share and share under optimal reallocation of land use according to

371 DEA problem (B) that would have complied with the CAP's '2 or 3 crop rule'. Since all farms 
372 in the sample cover more than 30 hectares, the most stringent rule would have been applied. All

373 farms should have produced at least three crops, where the main crop should not have covered 374 more than $75 \%$ of the arable land and the two main crops together not more than $95 \% .57 \%$ of 375 the observations would have complied with the ' 2 or 3 crop rule'. However, if farms would 376 have optimally reallocated their land use, this share increases to $84 \%$. This pattern is consistent 377 for the whole time period.

378 INSERT TABLE 4 AROUND HERE

\section{4.2. Robustness Checks}

380 We conduct three robustness checks. First, we investigate the results for the subsample of farms that obtain current-value profits close to their optimal level. Our opportunity cost measure assumes that farms would reallocate land use so as to maximise profit in the long run. Along the lines of Wossink and Swinton (2007), we thus assume that farms are only interested in crop diversification to the extent that it increases current-value profit. However, some farmers may not operate under this behavioural assumption as they are motivated by social and lifestyle goals (Howley, 2015). This robustness check thus focuses on the farms who are likely interested in dynamic profit maximisation. Second, we check the results for the subsample excluding outliers. Such a robustness check is useful as DEA is sensitive to outliers. Third, we investigate the results using the FDH approach, which relaxes the convexity assumption of the technology set. All tables for the robustness checks can be found in the Online Appendix.

\subsubsection{Non-Profit-Maximising Behaviour}

392 Table B1 shows the share of farms that have a dynamic profit efficiency of $80 \%$ or more for 393 DEA problems (A) and (B). We only take into account the farms that have a positive maximum 394 current-value profit for DEA problems (A) and (B) ${ }^{3} .36 \%$ of the observations have a dynamic 395 profit efficiency of $80 \%$ or more for DEA problem (A). The share ranges from $30 \%$ (in 2011) 396 to $52 \%$ (in 2007). $26 \%$ of the observations have a dynamic profit efficiency of $80 \%$ or more for 397 DEA problem (B). The share ranges from 16\% (in 2009) to $41 \%$ (in 2007).

398 There are thus many observations with resource allocations deviating greatly from the long-run 399 profit-maximising point. This may indicate that the concerned farms are not long-term profit

\footnotetext{
${ }^{3}$ Since total land is implemented as a fixed factor, the maximum current-value profit is negative for several observations, especially for bad years such as 2009.
} 
400

401

402

403

404

405

406

407

408

409

410

411

412

413

414

415

416

417

418

419

420

421

422

423

424

425

426

427

428

maximisers ${ }^{4}$. Table B2 inspects the opportunity costs for the farms that have a dynamic profit efficiency (i.e., ratio of actual current-value profit to maximum current-value profit) of $80 \%$ or more for DEA problems (A) and (B). As for the general results, the computed opportunity costs are on average negative and are only positive on average for one year. Their average opportunity cost is $-£ 69$ for the period, ranging from $-£ 302$ (in 2008) to $£ 27$ (in 2011).

On average $47 \%$ of the farms with a dynamic profit efficiency of $80 \%$ or more for DEA problem (B) have a negative opportunity cost, while $17 \%$ have a positive cost. Only in the year 2011, did the number of farms with a positive opportunity cost exceed the number of farms with a negative opportunity cost. Observe that the dynamically profit efficient farms following DEA problem (B) (36\%) have by definition zero opportunity cost of crop diversification, as their land allocation should not be changed.

Table B3 shows the actual share and share under optimal reallocation of land use according to DEA problem (B) that would have complied with the CAP's '2 or 3 crop rule' for the farms with a dynamic profit efficiency of $80 \%$ or more. $57 \%$ of these observations would have complied with the ' 2 or 3 crop rule'. If farms would have optimally reallocated their land use, this share increases to $75 \%$. This pattern is consistent for the whole time period (except for the year 2010, where the estimated share for DEA problem (B) is equal to the actual share).

\subsubsection{Outliers}

Following Oude Lansink and Silva (2004), we truncate the original sample by excluding observations that are at least two standard deviations from the mean, to check the robustness to outliers. Table $\mathrm{C} 1$ shows the opportunity costs of this truncated subsample. The resulting opportunity costs are on average negative for each year. Their average opportunity cost is $-£$ 28 for the period, ranging from - $£ 91$ (in 2013) to $-£ 3$ (in 2010). 43\% of the farms from the truncated subsample have a negative opportunity cost and $17 \%$ a positive cost.

Table C2 reveals that more farms from the truncated subsample would comply with the ' 2 or 3 crop rule' if they would have optimally reallocated their land use. Dynamic profit maximisation allowing for reallocation of land use leads to an increase in compliance from $57 \%$ to $84 \%$. This pattern is consistent for the whole period.

\subsubsection{Non-Convexity}

\footnotetext{
${ }^{4}$ Obtaining the shadow price by using the dual relationship of the value function to the distance function faces a similar issue, as this depends on an arbitrary projection to the technological frontier. This is particularly a problem for very inefficient farms where the shadow price is sensitive to the choice of the directional vector or orientation.
} 
Table D1 shows the opportunity costs of crop diversification using the FDH model. The resulting opportunity costs are on average $£ 35$ considering the whole period, with a minimum of $-£ 21$ (in 2008) and a maximum of $£ 77$ (in 2010). 31\% (15\%) of the farms have a negative (positive) opportunity cost. This pattern holds for the whole period. Note that the FDH model allows for non-convexity of the technology set, but results in reduced detection of nonoptimising farms. Therefore, the share of farms with a zero opportunity cost is high (55\%).

Table D2 shows the actual share and share under optimal reallocation of land use according to problem (B) adjusted for non-convexity that would have complied with the CAP's ' 2 or 3 crop rule'. Dynamic profit maximisation allowing for reallocation of land use leads to an increase in compliance from $57 \%$ to $67 \%$. This pattern is consistent for the whole period. Again, these gains are somewhat more modest due to a lower detection of non-optimising farms inherent to the FDH model.

\subsection{Comparison to Usual Shadow-Pricing Approach}

The prevailing negative opportunity costs contrast with the imposed non-negative shadow prices of the usual approach of modelling environmental goods as conventional outputs in a distance function framework. Sipiläinen and Huhtala (2013) also computed the opportunity cost of the Shannon index for crop diversity using the distance function's dual relationship to the value function. They found an average opportunity cost between $£ 12$ and $£ 45$ (in constant 2007 terms) per 0.1 ha for a sample of Finnish cereal farms. We apply their approach for comparison (see Appendix E) and show the results in table 5. We run their model for each farm in the sample in each year to ensure comparability with our proposed approach. The estimated shadow price is $£ 79$ for the period, ranging from $£ 22$ (in 2008) to $£ 212$ (in 2013). As expected, these results are non-negative, which contradict the results of our introduced opportunity cost measure.

INSERT TABLE 5 AROUND HERE

\section{Discussion}

Our main finding is that dynamic profit-maximisation allowing for optimal land reallocation is generally associated with an increase in the Shannon index for crop diversity. The opportunity cost of crop diversification is mostly negative and most farms would have complied with the ' 2 or 3 crop rule' recently imposed by the CAP if they had optimally reallocated their land use. These results are robust to excluding observations far from the dynamic profit-maximising point, excluding outliers, and allowing non-convexity of the technology set. Negative 
462

463

464

465

466

467

468

469

470

471

472

473

474

475

476

477

478

479

480

481

482

483

484

485

486

487

488

489

490

491

492

493

494

opportunity costs could not have been obtained by exploiting the distance function's dual relationship to the value function as commonly done in the literature. Our results are in line with the conceptual and empirical work of respectively Wossink and Swinton (2007) and Sauer and Wossink (2013), who argue that many farms would be willing to pay to increase the provision of environmental goods as its relationship with conventional production is not purely competitive. This coincides with the ecological perspective that environmental measures may be needed for long-term economic benefits.

Since nonparametric models are in essence deterministic, we have implicitly assumed that farms can perfectly foresee the outcomes of their production decisions. However, there is in reality considerable uncertainty in agricultural production due to unforeseen weather conditions. As a result, our model may compare farms that have different output realisations due to different 'States of Nature' (Quiggin and Chambers, 2006). We partially control for this issue by running the DEA models per year. For instance, since 2009 clearly marks a year with a bad State of Nature, the reference technology only consists of observations for the year 2009 . One could consider controlling for this issue even more by also running the DEA models per government office region. However, subdividing our sample into smaller subsamples leads to dimensionality problems given the large number of inputs, outputs and net investments in dynamic factors compared to the relatively low number of observations. Moreover, all farms considered are located in the East of England, which is a fairly homogeneous region with similar weather conditions. This ensures that the bias due to different States of Nature at the time of production is small. Note that our findings are persistent for each of the seven years considered, hold for the subsample of farms with a dynamic profit efficiency of $80 \%$ or more, is robust to excluding extreme observations, and hold for a non-convex production technology.

In the light of the 'Green Direct Payment' measure introduced recently by the CAP, we may reflect on whether the relative robustness of our results translates into predictive power. On the one hand, the predicted potential is possibly underestimated. We have aggregated spring and winter crops as these belong to the same species. However, according to the ' 2 or 3 crop rule', spring and winter crops can be counted as separate crops. Also fallow land can be counted separately according to this rule. Although we take this into account in our calculations, these are assumed to be non-reallocatable inputs that jointly contribute to the production of marketable outputs. In addition, it is plausible that farmers use crop diversification as a riskreducing mechanism, even if it would lead to lower rather than higher expected profits (Di Falco and Chavas, 2008; Di Falco and Chavas, 2009). On the other hand, there are also several reasons 
to believe that the predicted potential is overestimated. There is plenty of evidence of persistent

496 inefficient behaviour due to inherent non-economic objectives (Howley, 2015) or persistent technical inefficiency (Emvalomatis, Stefanou et al., 2011). Such dynamic profit inefficiency is also present in the current study. Moreover, although dynamic profit maximisation would lead to a shift to more profitable products such as barley, this remains constrained by market conditions and limitations on crop rotation. In summary, although our findings suggest no general justification of subsidisation of crop diversification, we remain cautious about the predictive power of our model.

\section{Conclusions}

504 Distance functions are increasingly being augmented with environmental goods treated as outputs to assess the trade-off between environmental goods and outputs. A common approach to evaluate the opportunity cost of providing an environmental good is the exploitation of the distance function's dual relationship to the value function. However, this approach may rely on problematic assumptions about the environmental goods' axiomatic properties. In particular, it is assumed that an environmental good can be treated as a conventional, strongly disposable output and that its shadow price is as a result always non-negative. Moreover, the convexity assumption of the augmented environmental technology set is necessary to ensure that the output distance function's dual relationship to the revenue function holds.

513 Focusing on crop diversification, this paper develops an opportunity cost measure that 514 overcomes these drawbacks for a sample of English cereal farms covering the years 2007-2013. 515 Using a nonparametric model, we assess the extent to which reallocation of land use can increase current-value profit. As this increase is linked to a change of the Shannon index for crop diversity, this allows us to express the opportunity cost of crop diversification in terms of

518 foregone current-value profit. Our proposed measure relies solely on standard axiomatic 519 properties of conventional inputs and outputs, does not critically depend on convexity of the technology set, and is consistent with the behavioural assumption of dynamic profitmaximisation. Our results are robust to excluding observations far from the dynamic profitmaximising point, excluding outliers, and relaxing the convexity assumption of the technology set.

524 The results show that the opportunity cost of crop diversification is mostly negative. This is an 525 interesting outcome, as distance functions augmented with environmental goods treated as 526 outputs implicitly assume that shadow prices of environmental goods are always non-negative. 527 The results also indicate that optimal reallocation of land use, which would have maximised 
528 dynamic profit, would have led to increased compliance with the CAP's recently introduced '2 529 or 3 crop rule'. These results may be interpreted that crop diversification does not generally 530 justify subsidies, suggesting a reconsideration of the financial mechanism of the CAP's Green 531 Direct Payment measure. However, we remain cautious about the general policy implications 532 of the results, for we have focused on a sample of specialised farms in a particular region (East 533 of England). Additionally, we have observed high dynamic profit inefficiency, which is likely 534 to persist after the introduction of the ' 2 or 3 crop rule'. Finally, market conditions and 535 limitations on crop rotation may limit shifts to the dynamic profit-maximising land allocation.

536 We have several suggestions for future research. First, there is a demand from policy makers to 537 develop a holistic sustainability measure which incorporates environmental goods and bads in 538 a rigorous way. Understanding the trade-offs among inputs, outputs, and environmental goods 539 and bads is essential to this end. Our measure has explicitly separated the environmental good 540 from the production technology. There could be other ways to realistically model environmental 541 goods and bads within the production technology. Murty, Russell et al. (2012) develop distance 542 functions that specifically model the pollution-generating inputs. It may be worthwhile to also 543 model the inputs that generate environmental goods. Second, our measure can be augmented 544 by taking into account spatial heterogeneity, which occurs due to different environmental 545 circumstances and market conditions (Polasky, Nelson et al., 2008; Nelson, Mendoza et al., 546 2009). Third, our measure can be extended by accounting for risk along the lines of Chavas and 547 Di Falco (2012), since crop diversification is an important mechanism of risk reduction, 548 potentially at the expense of expected profits. 


\section{On-Line Appendix A}

550 Following Kuosmanen, Kortelainen et al. (2010), we solve the following linear problem to find 551 values for $W_{K}($.$) for each farm j \in \mathbb{R}_{+}^{J}$ :

552

(C)

$$
\min _{\left\{p, w, v, W_{K}, \rho\right\}} \rho
$$

s.t.

(C.1) $\quad \rho \geq\left(p^{\prime} y-w^{\prime} x-v^{\prime} L+W_{K}^{\prime}(I-\delta K)\right)-\left(p^{\prime} y_{i}-w^{\prime} x_{i}-v^{\prime} L_{i}+W_{K}^{\prime}\left(I_{i}-\right.\right.$

$$
\left.\left.\delta_{i} K_{i}\right)\right), i=1, \ldots, J
$$

$$
\text { (C.2) } \quad p^{\prime} g_{y}+w^{\prime} g_{x}+v^{\prime} g_{L}+W_{K}^{\prime} g_{I}=1,\left(g_{y}, g_{x}, g_{I}, g_{L}\right)=\left(\frac{1}{p}, 0,0,0\right)
$$$$
\text { (C.3) } \quad p^{\prime} g_{y}+w^{\prime} g_{x}+v^{\prime} g_{L}+W_{K}^{\prime} g_{I}=1,\left(g_{y}, g_{x}, g_{I}, g_{L}\right)=\left(0, \frac{1}{w}, 0,0\right)
$$

$$
\text { (C.4) } \quad p \geq 0
$$

where $y \in \mathbb{R}_{+}^{1}$ is the aggregated output vector, $x \in \mathbb{R}_{+}^{1}$ is the aggregated variable input vector, $K_{t} \in \mathbb{R}_{+}^{F}$ is the initial capital stock vector, $I \in \mathbb{R}_{+}^{F}$ is the investment vector, $L \in \mathbb{R}_{+}^{2}$ is the vector of fixed factors consisting of total agricultural land area and family labor, $p \in \mathbb{R}_{+}^{1}$ is the vector of aggregated output prices, $w \in \mathbb{R}_{+}^{1}$ is the vector of aggregated input prices, $v \in \mathbb{R}_{+}^{2}$ is the vector of fixed factor prices, $c \in \mathbb{R}_{+}^{F}$ is the vector of capital prices, $W_{K} \in \mathbb{R}_{+}^{F}$ is the vector of shadow values of capital, $\delta$ is a diagonal $F \times F$ matrix of depreciation rates $\delta_{f}>0, f, \ldots, F$ $\left(g_{y}, g_{x}, g_{I}, g_{L}\right)$ is the directional vector in terms of outputs, inputs, investment and fixed factors. Outputs and inputs are aggregated by Törnqvist price indexes to reduce dimensionality. This means that quality differences are assumed to be revealed by the implicit quantity (Cox and Wohlgenant, 1986). This model is run per year. It also solves for the prices $v \in \mathbb{R}_{+}^{2}$ of the vector of fixed factors (total land and family labour). By setting $\left(g_{y}, g_{x}, g_{L}, g_{I}\right)=\left(\frac{1}{p}, 0,0,0\right)$

573 and $\left(g_{y}, g_{x}, g_{L}, g_{I}\right)=\left(0, \frac{1}{w}, 0,0\right)$ in respectively C.2 and C.3, we ensure that $L$ is treated as a vector of fixed factors and the known information on output and input prices is incorporated in the model. The farm-specific values for $W_{K}$ are plugged into DEA problems (A) and (B). 


\section{On-Line Appendix B}

577 Table B1. Share of farms with a dynamic profit efficiency of $80 \%$ or more for DEA problems (A) and (B), $578 \quad 2007-2013$

\begin{tabular}{lll}
\hline Year & Share for DEA problem $(\mathrm{A})$ & Share for DEA problem $(\mathrm{B})$ \\
\hline 2007 & $52 \%$ & $41 \%$ \\
2008 & $43 \%$ & $39 \%$ \\
2009 & $30 \%$ & $16 \%$ \\
2010 & $32 \%$ & $18 \%$ \\
2011 & $30 \%$ & $27 \%$ \\
2012 & $32 \%$ & $20 \%$ \\
2013 & $34 \%$ & $23 \%$ \\
& & \\
Period & $36 \%$ & $26 \%$ \\
\hline
\end{tabular}

579

580 Table B2. Opportunity costs of the Shannon index for crop diversification per 0.1 ha for farms with a 581 dynamic profit efficiency of $80 \%$ or more for DEA problem (B) using the proposed method, 2007-2013

\begin{tabular}{lllllll}
\hline Year & $\begin{array}{l}\text { Number of } \\
\text { farms }\end{array}$ & $\begin{array}{l}\text { Average (in } \\
\text { constant 2007 f) }\end{array}$ & $\begin{array}{l}\text { Std. Dev. (in } \\
\text { constant 2007 })\end{array}$ & & Share & \\
& & & & Negative & 0 & Positive \\
\hline 2007 & 18 & -17 & 169 & $39 \%$ & $50 \%$ & $11 \%$ \\
2008 & 17 & -302 & 1342 & $59 \%$ & $29 \%$ & $12 \%$ \\
2009 & 7 & -1 & 3 & $29 \%$ & $71 \%$ & $0 \%$ \\
2010 & 8 & -14 & 42 & $38 \%$ & $38 \%$ & $25 \%$ \\
2011 & 12 & 27 & 47 & $33 \%$ & $25 \%$ & $42 \%$ \\
2012 & 9 & -12 & 46 & $44 \%$ & $22 \%$ & $33 \%$ \\
2013 & 10 & -22 & 24 & $80 \%$ & $20 \%$ & $0 \%$ \\
& & & & & & $17 \%$ \\
\hline
\end{tabular}

582 
584 Table B3. Actual share and share under optimal reallocation of land use according to DEA problem (B)

585 that would have complied with the CAP's ' 2 or 3 crop rule' for farms with a dynamic profit efficiency of $586 \quad \mathbf{8 0 \%}$ or more, $2007-2013$

\begin{tabular}{lllllr}
\hline Year & Actual share & $\begin{array}{l}\text { Estimated share for DEA } \\
\text { problem (B) }\end{array}$ & $\begin{array}{l}\text { Gains from } \\
\text { reallocation in } \\
\text { units }\end{array}$ & $\begin{array}{r}\text { optimal } \\
\text { percentage }\end{array}$ \\
\hline 2007 & $61 \%$ & $72 \%$ & $+11 \%$ & \\
2008 & $47 \%$ & $71 \%$ & $+24 \%$ & \\
2009 & $57 \%$ & $86 \%$ & $+19 \%$ & \\
2010 & $63 \%$ & $63 \%$ & $+0 \%$ & \\
2011 & $58 \%$ & $83 \%$ & $+25 \%$ & \\
2012 & $56 \%$ & $78 \%$ & $+22 \%$ & \\
2013 & $60 \%$ & $80 \%$ & $+20 \%$ & \\
& & & & $+17 \%$ & \\
\hline
\end{tabular}

587

588 


\section{On-Line Appendix C}

590 Table C1. Opportunity costs of the Shannon index for crop diversification per 0.1 ha for subsample 591 excluding outliers, 2007-2013

\begin{tabular}{lllllll}
\hline Year & $\begin{array}{l}\text { Number of } \\
\text { farms }\end{array}$ & $\begin{array}{l}\text { Average (in } \\
\text { constant 2007 £) }\end{array}$ & $\begin{array}{l}\text { Std. Dev. (in } \\
\text { constant 2007 }\end{array}$ & & & Share \\
& & & & Negative & 0 & Positive \\
\hline 2007 & 42 & -9 & 105 & $55 \%$ & $26 \%$ & $19 \%$ \\
2008 & 43 & -25 & 144 & $72 \%$ & $19 \%$ & $9 \%$ \\
2009 & 43 & -15 & 210 & $77 \%$ & $19 \%$ & $5 \%$ \\
2010 & 41 & -3 & 75 & $59 \%$ & $24 \%$ & $17 \%$ \\
2011 & 43 & -42 & 163 & $58 \%$ & $19 \%$ & $23 \%$ \\
2012 & 43 & -28 & 240 & $65 \%$ & $16 \%$ & $19 \%$ \\
2013 & 43 & -91 & 174 & $81 \%$ & $12 \%$ & $7 \%$ \\
& & & 169 & & & $14 \%$ \\
\hline
\end{tabular}

592

593 Table C2. Actual share and share under optimal reallocation of land use according to DEA problem (B)

594 that would have complied with the CAP's ' 2 or 3 crop rule' for subsample excluding outliers, 2007-2013

\begin{tabular}{|c|c|c|c|}
\hline Year & Actual share & $\begin{array}{l}\text { Estimated share for DEA } \\
\text { problem (B) }\end{array}$ & $\begin{array}{l}\text { Gains in share from optimal } \\
\text { reallocation in percentage } \\
\text { units }\end{array}$ \\
\hline 2007 & $50 \%$ & $76 \%$ & $+26 \%$ \\
\hline 2008 & $51 \%$ & $88 \%$ & $+37 \%$ \\
\hline 2009 & $60 \%$ & $98 \%$ & $+37 \%$ \\
\hline 2010 & $56 \%$ & $80 \%$ & $+24 \%$ \\
\hline 2011 & $53 \%$ & $72 \%$ & $+29 \%$ \\
\hline 2012 & $58 \%$ & $84 \%$ & $+26 \%$ \\
\hline 2013 & $67 \%$ & $91 \%$ & $+23 \%$ \\
\hline Period & $57 \%$ & $84 \%$ & $+28 \%$ \\
\hline
\end{tabular}

595

596 


\section{On-Line Appendix D}

598 Table D1. Opportunity costs of the Shannon index for crop diversification per 0.1 ha using the proposed 599 method adjusted for non-convexity, 2007-2013

\begin{tabular}{lllllll}
\hline Year & $\begin{array}{l}\text { Number of } \\
\text { farms }\end{array}$ & $\begin{array}{l}\text { Average (in } \\
\text { constant 2007 }\end{array}$ & $\begin{array}{l}\text { Std. Dev. (in } \\
\text { constant 2007 £) }\end{array}$ & Negative & 0 & Positive \\
\hline 2007 & 44 & 13 & & $23 \%$ & $55 \%$ & $23 \%$ \\
2008 & 44 & -35 & 164 & $27 \%$ & $57 \%$ & $16 \%$ \\
2009 & 44 & -21 & 286 & $39 \%$ & $39 \%$ & $23 \%$ \\
2010 & 44 & 77 & 97 & $39 \%$ & $55 \%$ & $7 \%$ \\
2011 & 44 & 16 & 639 & $34 \%$ & $57 \%$ & $9 \%$ \\
2012 & 44 & 23 & 202 & $25 \%$ & $64 \%$ & $11 \%$ \\
2013 & 44 & 70 & 532 & $27 \%$ & $57 \%$ & $16 \%$ \\
& & & & & & $15 \%$ \\
\hline
\end{tabular}

600

601 Table D2. Actual share and share under optimal reallocation of land use according to problem (B) adjusted 602 for non-convexity that would have complied with the CAP's '2 or 3 crop rule'

\begin{tabular}{|c|c|c|c|}
\hline Year & Actual share & $\begin{array}{l}\text { Estimated share for problem } \\
\text { (B) adjusted for non- } \\
\text { convexity }\end{array}$ & $\begin{array}{l}\text { Gains from optimal } \\
\text { reallocation in percentage } \\
\text { units }\end{array}$ \\
\hline 2007 & $52 \%$ & $57 \%$ & $+5 \%$ \\
\hline 2008 & $52 \%$ & $64 \%$ & $+11 \%$ \\
\hline 2009 & $61 \%$ & $75 \%$ & $+14 \%$ \\
\hline 2010 & $57 \%$ & $73 \%$ & $+16 \%$ \\
\hline 2011 & $55 \%$ & $66 \%$ & $+11 \%$ \\
\hline 2012 & $57 \%$ & $66 \%$ & $+9 \%$ \\
\hline 2013 & $68 \%$ & $70 \%$ & $+2 \%$ \\
\hline Period & $57 \%$ & $67 \%$ & $+10 \%$ \\
\hline
\end{tabular}

603

604 
605

606

607

608

609

610

611

612

613

614

615

616

617

618

619

620

621

622

623

624

625

626

627

628

629

630

631

632

\section{On-Line Appendix E}

We exploit the directional distance function's dual relationship to the profit function by solving a minimax problem similar to linear program (C) in line with Kuosmanen, Kortelainen et al. (2010). We solve the following linear problem to find shadow price $u$ for each farm $j \in \mathbb{R}_{+}^{J}$ :

(D) $\min _{\{p, w, v, u, \theta\}} \theta$

s.t.

(D.1) $\quad \theta \geq\left(p^{\prime} y-w^{\prime} x-v^{\prime} L+u^{\prime} S(.)^{(1)}\right)-\left(p^{\prime} y_{i}-w^{\prime} x_{i}-v^{\prime} L_{i}+u^{\prime} S(.)^{(1)}\right), i=$

$$
1, \ldots, J
$$

(D.2) $\quad p^{\prime} g_{y}+w^{\prime} g_{x}+v^{\prime} g_{L}+u^{\prime} g_{S}=1,\left(g_{y}, g_{x}, g_{L}, g_{S}\right)=\left(\frac{1}{p}, 0,0,0\right)$

(D.3) $\quad p^{\prime} g_{y}+w^{\prime} g_{x}+v^{\prime} g_{L}+u^{\prime} g_{S}=1,\left(g_{y}, g_{x}, g_{L}, g_{S}\right)=\left(0, \frac{1}{w}, 0,0\right)$

(D.4) $\quad p \geq 0$

(D.5) $\quad w \geq 0$

(D.6) $\quad v \geq 0$

(D.7) $\quad u \geq 0$

where $y \in \mathbb{R}_{+}^{1}$ is the aggregated output vector, $x \in \mathbb{R}_{+}^{1}$ is the aggregated variable input vector, $L \in \mathbb{R}_{+}^{2}$ is the vector of fixed factors consisting of total agricultural land area and family labour, $S(.)^{(1)}$ is the Shannon index for crop diversity computed by Eq. (9), $p \in \mathbb{R}_{+}^{1}$ is the vector of aggregated output prices, $w \in \mathbb{R}_{+}^{1}$ is the vector of aggregated input prices, $v \in \mathbb{R}_{+}^{2}$ is the vector of fixed factor prices, $u \in \mathbb{R}_{+}^{1}$ is the vector of shadow values of capital, $\delta$ is a diagonal $F \times F$ matrix of depreciation rates $\delta_{f}>0, f, \ldots, F .\left(g_{y}, g_{x}, g_{L}, g_{S}\right)$ is the directional vector in terms of outputs, inputs, fixed factors and the Shannon index for crop diversity. Outputs and inputs are aggregated by Törnqvist price indexes to reduce dimensionality. This means that quality differences are assumed to be revealed by the implicit quantity (Cox and Wohlgenant, 1986). This model is run per year. It also solves for the prices $v \in \mathbb{R}_{+}^{2}$ of the vector of fixed factors (total land and family labor). By setting $\left(g_{y}, g_{x}, g_{L}, g_{S}\right)=\left(\frac{1}{p}, 0,0,0\right)$ and $\left(g_{y}, g_{x}, g_{L}, g_{S}\right)=$ $\left(0, \frac{1}{w}, 0,0\right)$ in respectively C.2 and C.3, we ensure that $L$ is treated as a vector of fixed factors and the known information on output and input prices is incorporated in the model. 


\section{References}

Aguilar, J., G.G. Gramig, J.R. Hendrickson, D.W. Archer, F. Forcella and M.A. Liebig "Crop Species Diversity Changes in the United States: 1978-2012." PLoS ONE, Vol. 10, (2015) pp. e0136580.

Ang, F. and P.J. Kerstens "To Mix or Specialise? A Coordination Productivity Indicator for English and Welsh farms." Journal of Agricultural Economics, Vol. 67, (2016) pp. 779-798.

Ang, F. and P.J. Kerstens "Decomposing the Luenberger-Hicks-Moorsteen Total Factor Productivity indicator: An application to US agriculture." European Journal of Operational Research, Vol. 260, (2017) pp. 359-375.

Ang, F. and A. Oude Lansink Decomposing Dynamic Profit Inefficiency of Belgian Dairy Farms, 2016).

Ang, F. and A. Oude Lansink "Decomposing dynamic profit inefficiency of Belgian dairy farms." European Review of Agricultural Economics, (2017) pp. 1-19.

Areal, F.J., R. Tiffin and K.G. Balcombe "Provision of environmental output within a multioutput distance function approach." Ecological Economics, Vol. 78, (2012) pp. 47-54.

Bellenger, M.J. and A.T. Herlihy "An economic approach to environmental indices." Ecological Economics, Vol. 68, (2009) pp. 2216-2223.

Bellenger, M.J. and A.T. Herlihy "Performance-based environmental index weights: Are all metrics created equal?" Ecological Economics, Vol. 69, (2010) pp. 1043-1050.

Bostian, M.B. and A.T. Herlihy "Valuing tradeoffs between agricultural production and wetland condition in the U.S. Mid-Atlantic region." Ecological Economics, Vol. 105, (2014) pp. 284-291. 
656 Briec, W., K. Kerstens and P.V. Eeckaut "Non-convex Technologies and Cost Functions: Definitions, Duality and Nonparametric Tests of Convexity." Journal of Economics, Vol. 81, (2004) pp. 155-192.

Chambers, R.G., T. Serra and A. Oude Lansink "On the pricing of undesirable statecontingent outputs." European Review of Agricultural Economics, Vol. 41, (2014) pp. 485-509.

Chavas, J.-P. and S. Di Falco "On the Role of Risk Versus Economies of Scope in Farm Diversification With an Application to Ethiopian Farms." Journal of Agricultural Economics, Vol. 63, (2012) pp. 25-55.

Cherchye, L., B. De Rock, B. Dierynck, F. Roodhooft and J. Sabbe "Opening the "Black Box" of Efficiency Measurement: Input Allocation in Multioutput Settings." Operations Research, Vol. 61, (2013) pp. 1148-1165.

Cherchye, L., B. De Rock and V. Hennebel "Coordination efficiency in multi-output settings: a DEA approach." Annals of Operations Research, (2015) pp. 1-29.

Cherchye, L., B. De Rock and V. Hennebel "Coordination efficiency in multi-output settings: a DEA approach." Annals of Operations Research, Vol. 250, (2017) pp. 205-233.

Coelli, T., L. Lauwers and G. Van Huylenbroeck "Environmental efficiency measurement and the materials balance condition." Journal of Productivity Analysis, Vol. 28, (2007) pp. $3-12$.

Cox, T.L. and M.K. Wohlgenant "Prices and Quality Effects in Cross-Sectional Demand Analysis." American Journal of Agricultural Economics, Vol. 68, (1986) pp. 908-919.

Dakpo, K.H., P. Jeanneaux and L. Latruffe "Greenhouse gas emissions and efficiency in French sheep meat farming: A non-parametric framework of pollution-adjusted technologies." European Review of Agricultural Economics, Vol. 44, (2017) pp. 3365. 
681 Di Falco, S. and J.-P. Chavas "Rainfall shocks, resilience, and the effects of crop biodiversity on agroecosystem productivity." Land Economics, Vol. 84, (2008) pp. 83-96.

Di Falco, S. and J.-P. Chavas "On Crop Biodiversity, Risk Exposure, and Food Security in the Highlands of Ethiopia." American Journal of Agricultural Economics, Vol. 91, (2009) pp. 599-611.

Emvalomatis, G., S.E. Stefanou and A. Oude Lansink "A Reduced-Form Model for Dynamic Efficiency Measurement: Application to Dairy Farms in Germany and The Netherlands." American Journal of Agricultural Economics, Vol. 93, (2011) pp. 161174.

European Parliament, C.o.t.E.U. "Regulation (EU) No 1307/2013 of the European Parliament and of the Council of 17 December 2013 establishing rules for direct payments to farmers under support schemes within the framework of the common agricultural policy and repealing Council Regulation (EC) No 637/2008 and Council Regulation (EC) No 73/2009", Official Journal of the European Union, 2013).

EUROSTAT, 2015).

Färe, R., R. Grabowski, S. Grosskopf and S. Kraft "Efficiency of a fixed but allocatable input: A non-parametric approach." Economics Letters, Vol. 56, (1997) pp. 187-193.

Färe, R. and S. Grosskopf New Directions: Efficiency and Productivity, Springer US, 2005).

Färe, R., S. Grosskopf and W.L. Weber "Shadow prices of Missouri public conservation land." Public Finance Review, Vol. 29, (2001) pp. 444-460.

Harvey, D.R. "Agri-environmental Relationships and Multi-functionality: Further Considerations." World Economy, Vol. 26, (2003) pp. 705-725.

Henry, M., P. Tittonell, R.J. Manlay, M. Bernoux, A. Albrecht and B. Vanlauwe "Biodiversity, carbon stocks and sequestration potential in aboveground biomass in 
smallholder farming systems of western Kenya." Agriculture, Ecosystems \& Environment, Vol. 129, (2009) pp. 238-252.

707

708

709

Hodge, I.D. "Agri-environmental relationships and the choice of policy mechanism." The World Economy, Vol. 23, (2000) pp. 257-273.

Hodge, I.D. To What Extent are Environmental Externalities a Joint Product of Agriculture?, OECD Publishing, 2008).

Howley, P. "The Happy Farmer: The Effect of Nonpecuniary Benefits on Behavior." American Journal of Agricultural Economics, Vol. 97, (2015) pp. 1072-1086.

Kuosmanen, T. "Duality Theory of Non-convex Technologies." Journal of Productivity Analysis, Vol. 20, (2003) pp. 273-304.

Kuosmanen, T., M. Kortelainen, T. Sipiläinen and L. Cherchye "Firm and industry level profit efficiency analysis using absolute and uniform shadow prices." European Journal of Operational Research, Vol. 202, (2010) pp. 584-594.

Macpherson, A.J., P.P. Principe and E.R. Smith "A directional distance function approach to regional environmental-economic assessments." Ecological Economics, Vol. 69, (2010) pp. 1918-1925.

Murty, S., R.R. Russell and S.B. Levkoff "On modeling pollution-generating technologies." Journal of Environmental Economics and Management, Vol. 64, (2012) pp. 117-135.

Nelson, E., G. Mendoza, J. Regetz, S. Polasky, H. Tallis, D. Cameron, K.M.A. Chan, G.C. Daily, J. Goldstein, P.M. Kareiva, E. Lonsdorf, R. Naidoo, T.H. Ricketts and M. Shaw "Modeling multiple ecosystem services, biodiversity conservation, commodity production, and tradeoffs at landscape scales." Frontiers in Ecology and the Environment, Vol. 7, (2009) pp. 4-11. 
Oude Lansink, A. and E. Silva "CO2 and energy efficiency of different heating technologies in the Dutch glasshouse industry." Environmental \& Resource Economics, Vol. 24, (2003) pp. 395-407.

Oude Lansink, A. and E. Silva "Non-parametric production analysis of pesticides use in the Netherlands." Journal of Productivity Analysis, Vol. 21, (2004) pp. 49-65.

Pimentel, D., P. Hepperly, J. Hanson, D. Douds and R. Seidel "Environmental, energetic, and economic comparisons of organic and conventional farming systems." Bioscience, Vol. 55, (2005) pp. 573-582.

Piot-Lepetit, I. and M. Le Moing "Productivity and environmental regulation: the effect of the nitrates directive in the French pig sector." Environmental \& Resource Economics, Vol. 38, (2007) pp. 433-446.

Piot-Lepetit, I. and D. Vermersch "Pricing organic nitrogen under the weak disposability assumption: An application to the French pig sector." Journal of Agricultural Economics, Vol. 49, (1998) pp. 85-99.

Polasky, S., E. Nelson, J. Camm, B. Csuti, P. Fackler, E. Lonsdorf, C. Montgomery, D. White, J. Arthur, B. Garber-Yonts, R. Haight, J. Kagan, A. Starfield and C. Tobalske "Where to put things? Spatial land management to sustain biodiversity and economic returns." Biological Conservation, Vol. 141, (2008) pp. 1505-1524.

Pope, B. and A. Johnson "Returns to scope: a metric for production synergies demonstrated for hospital production." Journal of Productivity Analysis, Vol. 40, (2013) pp. 239250.

Quiggin, J. and R.G. Chambers "The state-contingent approach to production under uncertainty*." The Australian Journal of Agricultural and Resource Economics, Vol. 50, (2006) pp. 153-169. 
Reinhard, S., C.A.K. Lovell and G. Thijssen "Econometric estimation of technical and environmental efficiency: An application to Dutch dairy farms." American Journal of Agricultural Economics, Vol. 81, (1999) pp. 44-60.

Reinhard, S., C.A.K. Lovell and G.J. Thijssen "Environmental efficiency with multiple environmentally detrimental variables; estimated with SFA and DEA." European Journal of Operational Research, Vol. 121, (2000) pp. 287-303.

Ruijs, A., M. Kortelainen, A. Wossink, C.J.E. Schulp and R. Alkemade "Opportunity Cost Estimation of Ecosystem Services." Environmental and Resource Economics, Vol. 66, (2017) pp. 717-747.

Ruijs, A., A. Wossink, M. Kortelainen, R. Alkemade and C.J.E. Schulp "Trade-off analysis of ecosystem services in Eastern Europe." Ecosystem Services, Vol. 4, (2013) pp. 82-94.

Sauer, J. and A. Wossink "Marketed outputs and non-marketed ecosystem services: the evaluation of marginal costs." European Review of Agricultural Economics, Vol. 40, (2013) pp. 573-603.

Serra, T., R.G. Chambers and A. Oude Lansink "Measuring technical and environmental efficiency in a state-contingent technology." European Journal of Operational Research, Vol. 236, (2014) pp. 706-717.

Silva, E., A. Oude Lansink and S.E. Stefanou "The adjustment-cost model of the firm: Duality and productive efficiency." International Journal of Production Economics, Vol. 168, (2015) pp. 245-256.

Silva, E. and S.E. Stefanou "Nonparametric dynamic production analysis and the theory of cost." Journal of Productivity Analysis, Vol. 19, (2003) pp. 5-32.

Sipiläinen, T. and A. Huhtala "Opportunity costs of providing crop diversity in organic and conventional farming: would targeted environmental policies make economic sense?" European Review of Agricultural Economics, Vol. 40, (2013) pp. 441-462. 
777 Varian, H.R. "The nonparametric approach to production analysis." Econometrica, Vol. 52, (1984) pp. 579-597.

779 Vatn, A. "Multifunctional agriculture: some consequences for international trade regimes." European Review of Agricultural Economics, Vol. 29, (2002) pp. 309-327.

Weitzman, M.L. "Economic Profitability Versus Ecological Entropy." The Quarterly Journal of Economics, Vol. 115, (2000) pp. 237-263.

783 Westbury, D.B., J.R. Park, A.L. Mauchline, R.T. Crane and S.R. Mortimer "Assessing the environmental performance of English arable and livestock holdings using data from the Farm Accountancy Data Network (FADN)." Journal of Environmental Management, Vol. 92, (2011) pp. 902-909.

787 Wossink, A. and S.M. Swinton "Jointness in production and farmers' willingness to supply non-marketed ecosystem services." Ecological Economics, Vol. 64, (2007) pp. 297304.

790 


\section{Tables}

793 Table 1. Descriptive statistics of the dataset (308 observations for 44 cereal farms), 2007-2013

\begin{tabular}{|c|c|c|c|}
\hline Variables & Unit & Mean & Std. Dev. \\
\hline \multicolumn{4}{|l|}{ Outputs } \\
\hline Wheat & Constant $2007 £$ & 173,175 & 242,325 \\
\hline Barley & Constant $2007 £$ & 7,815 & 16,023 \\
\hline Oats & Constant $2007 £$ & 3,583 & 9,818 \\
\hline Beans & Constant $2007 £$ & 4,242 & 14,516 \\
\hline Peas & Constant $2007 £$ & 8,184 & 31,342 \\
\hline Potatoes & Constant $2007 £$ & 51,797 & 75,696 \\
\hline Sugar beet & Constant $2007 £$ & 10,462 & 21,210 \\
\hline Other outputs & Constant $2007 £$ & 3,630 & 18,483 \\
\hline \multicolumn{4}{|l|}{ Output-specific land } \\
\hline Wheat & Hectares & 154 & 199 \\
\hline Barley & Hectares & 10 & 19 \\
\hline Oats & Hectares & 5 & 13 \\
\hline Beans & Hectares & 6 & 14 \\
\hline Peas & Hectares & 8 & 30 \\
\hline Potatoes & Hectares & 51 & 65 \\
\hline Sugar beet & Hectares & 6 & 12 \\
\hline Other outputs & Hectares & 3 & 12 \\
\hline \multicolumn{4}{|l|}{ Variable inputs } \\
\hline Seed and planting stock & Constant $2007 £$ & 28,186 & 41,084 \\
\hline Fertilizer & Constant $2007 £$ & 72,226 & 79,435 \\
\hline Crop protection & Constant $2007 £$ & 73,105 & 87,139 \\
\hline Electricity & Constant $2007 £$ & 2,995 & 6,091 \\
\hline Heating fuel & Constant $2007 £$ & 1,140 & 2,396 \\
\hline External labor & Annual working hours & 2,829 & 3,927 \\
\hline Management & Annual working hours & 16 & 114 \\
\hline Other variable inputs & Constant $2007 £$ & 9,714 & 14,144 \\
\hline \multicolumn{4}{|l|}{ Investments } \\
\hline Buildings & Constant $2007 £$ & 6,566 & 23,596 \\
\hline Machinery & Constant $2007 £$ & 54,093 & 88,128 \\
\hline \multicolumn{4}{|l|}{ Historical depreciation } \\
\hline Buildings & Constant $2007 £$ & 6,622 & 10,782 \\
\hline Machinery & Constant $2007 £$ & 31,078 & 38,539 \\
\hline \multicolumn{4}{|l|}{ Fixed non-reallocatable inputs } \\
\hline Grassland and other herbaceous forage & Hectares & 15 & 34 \\
\hline Fallow land & Hectares & 2 & 7 \\
\hline Family labour & Annual working hours & 1,865 & 822 \\
\hline
\end{tabular}


Table 2. Actual and maximum current-value profit and corresponding Shannon indexes for crop diversity

795 for DEA problems (A) and (B), 2007-2013

\begin{tabular}{|c|c|c|c|c|c|}
\hline Year & $\begin{array}{l}\text { Actual current- } \\
\text { value profit (in } \\
\text { constant } 2007 £ \text { ) }\end{array}$ & $\begin{array}{l}\text { Actual Shannon } \\
\text { index for crop } \\
\text { diversity }\end{array}$ & $\begin{array}{l}\text { Maximum current- } \\
\text { value profit for } \\
\text { DEA problem (A) } \\
\text { (in constant } 2007 \\
£ \text { ) }\end{array}$ & $\begin{array}{l}\text { Maximum current- } \\
\text { value profit for } \\
\text { DEA problem (B) } \\
\text { (in constant } 2007 \\
£ \text { ) }\end{array}$ & $\begin{array}{l}\text { Shannon index for } \\
\text { crop diversity for } \\
\text { DEA problem (B) }\end{array}$ \\
\hline 2007 & $154,483(314,419)$ & $0.87(0.34)$ & $170,212(310,268)$ & $195,978(324,841)$ & $1.10(0.37)$ \\
\hline 2008 & $120,307(173,665)$ & $0.81(0.35)$ & $140,512(168,810)$ & $175,024(180,673)$ & $1.15(0.33)$ \\
\hline 2009 & - 38,429 (126,077) & $0.88(0.34)$ & $5,724(100,200)$ & $51,696(105,261)$ & $1.29(0.25)$ \\
\hline 2010 & $122,038(220,333)$ & $0.85(0.41)$ & $144,279(217,925)$ & $178,307(229,371)$ & $1.16(0.40)$ \\
\hline 2011 & $176,152(272,026)$ & $0.82(0.34)$ & $225,998(271,740)$ & $278,024(294,843)$ & $0.96(0.26)$ \\
\hline 2012 & $210,096(428,709)$ & $0.82(0.33)$ & $270,091(421,990)$ & $304,165(425,447)$ & $1.06(0.34)$ \\
\hline 2013 & $122,651(206,530)$ & $0.89(0.38)$ & $145,034(200,918)$ & $185,223(214,574)$ & $1.19(0.31)$ \\
\hline Period & $123,900(273,035)$ & $0.85(0.35)$ & $157,407(269,026)$ & $195,488(279,285)$ & $1.13(0.34)$ \\
\hline
\end{tabular}

796

797

798

Table 3. Opportunity costs of the Shannon index for crop diversification per 0.1 ha using the proposed

799 method, 2007-2013

\begin{tabular}{lllllll}
\hline Year & $\begin{array}{l}\text { Number of } \\
\text { farms }\end{array}$ & $\begin{array}{l}\text { Average (in } \\
\text { constant 2007 £) }\end{array}$ & $\begin{array}{l}\text { Std. Dev. (in } \\
\text { constant 2007 £) }\end{array}$ & \multicolumn{3}{c}{ Share } \\
& & & & Negative & 0 & Positive \\
\hline 2007 & 44 & 34 & 290 & $55 \%$ & $25 \%$ & $20 \%$ \\
2008 & 44 & -149 & 830 & $73 \%$ & $18 \%$ & $9 \%$ \\
2009 & 44 & -244 & 1531 & $77 \%$ & $18 \%$ & $5 \%$ \\
2010 & 44 & -21 & 159 & $59 \%$ & $23 \%$ & $18 \%$ \\
2011 & 44 & -110 & 481 & $59 \%$ & $18 \%$ & $23 \%$ \\
2012 & 44 & -105 & 564 & $66 \%$ & $16 \%$ & $18 \%$ \\
2013 & 44 & -113 & 257 & $80 \%$ & $11 \%$ & $9 \%$ \\
& & & & & & \\
Period & 308 & -101 & 730 & $67 \%$ & $19 \%$ & $15 \%$ \\
\hline
\end{tabular}

800

801 
802 Table 4. Actual share and share under optimal reallocation of land use according to DEA problem (B)

803 that would have complied with the CAP's '2 or 3 crop rule', 2007-2013

\begin{tabular}{llll}
\hline Year & Actual share & $\begin{array}{l}\text { Estimated share for } \\
\text { problem }(\mathrm{B})\end{array}$ & $\begin{array}{c}\text { DEA } \\
\text { Gains in share from optimal } \\
\text { reallocation }\end{array}$ \\
\hline 2007 & $52 \%$ & $77 \%$ & $+25 \%$ \\
2008 & $52 \%$ & $89 \%$ & $+36 \%$ \\
2009 & $61 \%$ & $98 \%$ & $+36 \%$ \\
2010 & $57 \%$ & $80 \%$ & $+23 \%$ \\
2011 & $55 \%$ & $73 \%$ & $+18 \%$ \\
2012 & $57 \%$ & $82 \%$ & $+25 \%$ \\
2013 & $68 \%$ & $93 \%$ & $+25 \%$ \\
& & & \\
\hline
\end{tabular}

804

805

806 Table 5. Opportunity costs of the Shannon index for crop diversification per 0.1 ha using the directional

807 distance function approach, 2007-2013

\begin{tabular}{lllllll}
\hline Year & $\begin{array}{l}\text { Number of } \\
\text { farms }\end{array}$ & $\begin{array}{l}\text { Average (in } \\
\text { constant 2007 }\end{array}$ & $\begin{array}{l}\text { Std. Dev. (in } \\
\text { constant 2007 £) }\end{array}$ & Negative & 0 & Phare \\
& & & & 0 & $27 \%$ & $73 \%$ \\
2007 & 44 & 49 & 125 & 0 & $52 \%$ & $48 \%$ \\
2008 & 44 & 22 & 68 & 0 & $48 \%$ & $52 \%$ \\
2010 & 44 & 37 & 50 & 0 & $64 \%$ & $36 \%$ \\
2011 & 44 & 65 & 151 & 0 & $66 \%$ & $34 \%$ \\
2012 & 44 & 110 & 330 & 0 & $16 \%$ & $84 \%$ \\
2013 & 44 & 61 & 169 & 0 & $61 \%$ & $39 \%$ \\
& & 212 & 941 & & & $52 \%$ \\
\hline
\end{tabular}

808

809 


\section{$810 \quad$ Figures}

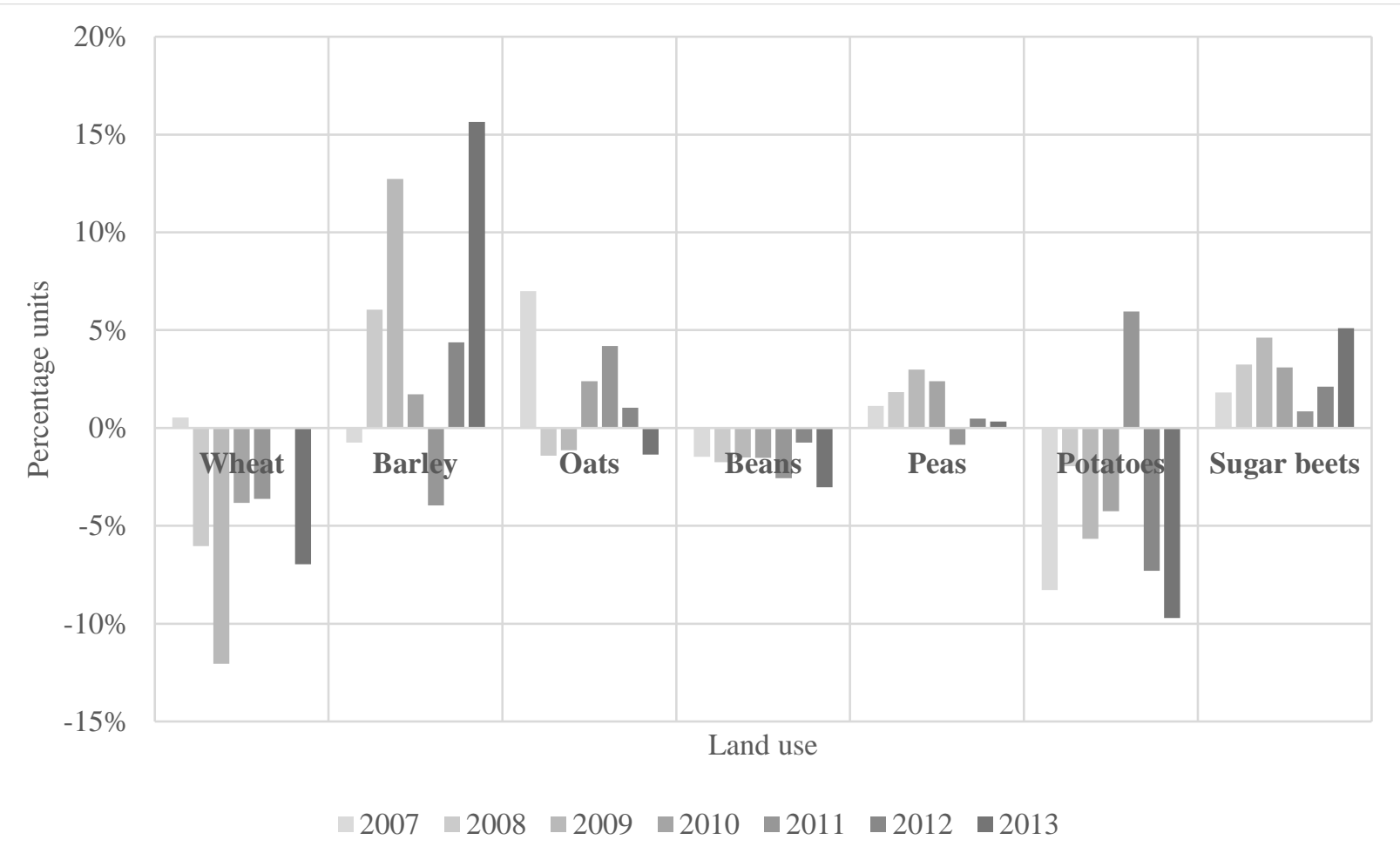

811

812 Figure 1. Change in land use required for dynamic profit maximisation, 2007-2013 (in percentage units) 